\title{
Gravity Receptor Aging in the CBA/CaJ Strain: A Comparison to Auditory Aging
}

\author{
Bruce Mock ${ }^{1}$, Timothy A. Jones ${ }^{1}$, And Sherri M. Jones ${ }^{1}$ \\ ${ }^{1}$ Department of Communication Sciences and Disorders, East Carolina University, Mail Stop 668, Greenville, NC 27858-4353, \\ USA
}

Received: 9 August 2010; Accepted: 21 October 2010; Online publication: 5 November 2010

\begin{abstract}
The CBA/CaJ mouse strain is commonly used as a control as it has no known genetic mutations affecting the inner ear, maintains hearing sensitivity throughout life, and serves as a background for creating new genetic strains. The purpose of the present study was to characterize the effects of age and gender on gravity receptor function and compare functional changes between auditory and vestibular modalities. Vestibular-evoked potentials (VsEPs), auditory brainstem responses (ABRs), and distortion product otoacoustic emissions were measured in 131 mice. VsEP thresholds deteriorated an average of $0.39 \mathrm{~dB}$ re: $1.0 \mathrm{~g} / \mathrm{ms}$ per month and at the oldest ages (1823 months old) showed an average loss of $49 \%$ of VsEP dynamic range. No significant gender differences were found for VsEPs. ABR thresholds increased by an average of $1.35,1.38$, and $1.15 \mathrm{~dB}$ pe SPL per month for ABR stimulus frequencies of 8 , 16 , and $32 \mathrm{kHz}$, respectively, demonstrating an average decrease in auditory dynamic range of 25$35 \%$ at advanced ages. Both modalities declined with age. Age-related decreases in gravity receptor sensitivity should be considered when using the $\mathrm{CBA} / \mathrm{CaJ}$ strain for vestibular studies.
\end{abstract}

Keywords: utricle, saccule, cochlea, vestibular, evoked potentials

Correspondence to: Sherri M. Jones · Department of Communication Sciences and Disorders - East Carolina University - Mail Stop 668, Greenville, NC 27858-4353, USA. Telephone: +1-252-7446087; fax: +1-252-7446109; email: jonessh@ecu.edu

\section{INTRODUCTION}

The inner ear houses the sensory organs for hearing and balance. Age-related cochlear change is wellcharacterized in the literature (e.g., Schuknecht and Gacek, 1993; reviews by Ohlemiller 2004, 2006; Ohlemiller and Frisina 2008) and predisposing factors such as gender, genetics, lifestyle, disease, and environmental causes have been identified. Age-related hearing loss (ARHL) is the most common cause of hearing impairment in humans, affecting $50 \%$ of the population by age 80 . The effects of age and predisposing factors to vestibular dysfunction are poorly understood, even though the National Institute on Deafness and other Communication Disorders estimated that $3.4 \%$ of the US adult population suffers from chronic dizziness/imbalance (Hoffman and Sklare 2003).

Vestibular functional changes in the inner ear during aging are difficult to measure. Typically, studies have utilized indirect measures such as the vestibulo-ocular-reflex (VOR), optokinetic response $(\mathrm{OKN})$, the otolith-ocular reflex, visual-vestibular responses, and tests of posture to make inferences about peripheral vestibular function (Paige 1992, 1994; Baloh et al. 1993; Enrietto et al. 1999; Shiga et al. 2005; Furman and Redfern 2001). In general, these studies have reported modest decreases in VOR gain, increased phase lead, decreased ability to suppress the VOR with vision, reduced shortening of the VOR time constant by post-rotary head tilt, and lower OKN slowphase velocity saturation.

Investigations by Jones et al. (2005, 2006) using direct measures of auditory (auditory brainstem response, ABR) and vestibular function (vestibular evoked potentials, VsEP) in a variety of inbred mouse 
strains suggested that genetic background may play a role in age-related changes in the two sensory systems. Furthermore, Jones et al. (2006) proposed that agerelated functional change in one sensory system does not obligate change in the other.

Mouse models have been a valuable tool in the investigation of predisposing factors and structural correlates of ARHL. The CBA/CaJ inbred mouse strain carries no known genetic mutations affecting the inner ear, maintains auditory sensitivity until late in life (Henry and McGinn 1992; Li and Borg 1991), and is commonly used as a control strain or as a genetic background for generating new mutant strains. Gender differences in ARHL have been reported in this strain with males showing greater hearing loss than females (Guimaraes et al. 2004).

In the current study, we posed the question: What are the effects of age and gender on gravity receptor function in comparison to auditory function? We hypothesized that: (1) changes in gravity receptor function are concurrent with age related functional changes in the cochlea; and (2) changes in gravity receptor function are the same for males and females.

Auditory and gravity receptor function were characterized in $131 \mathrm{CBA} / \mathrm{CaJ}$ mice ranging in age from 1.7 to 23.8 months of age. The ABR and distortion product otoacoustic emissions (DPOAEs) were used to assess auditory function and vestibular-evoked potentials (VsEPs) were used to assess gravity receptor function. Response parameters were compared between genders, across age, and the rates of change in sensitivity were compared between the two sensory modalities. Temporal bones were harvested following functional studies and scanning electron microscopy (SEM) was used to qualitatively characterize gravity receptor otoconia.

\section{METHODS}

\section{Animals and animal preparation}

Ambient noise levels in the animal housing area were monitored throughout the study to assure that levels were below those which might result in noise induced hearing loss. CBA/CaJ breeding pairs were obtained from The Jackson Laboratory (Bar Harbor, ME, USA) to produce offspring for testing. Animals were housed and maintained using standard husbandry methods until the appropriate age.

During testing, mice were anesthetized with ketamine $(90-126 \mathrm{mg} / \mathrm{kg})$ and xylazine $(10-14 \mathrm{mg} / \mathrm{kg})$ injected intraperitoneally. Body core temperature was maintained at $37.0 \pm 0.2^{\circ} \mathrm{C}$ using a homeothermic heating blanket and rectal thermocouple (FHC, Inc.). Mice were excluded from the study if there was any indication of outer or middle ear dysfunction (i.e., redness or inflammation of the external ear canal or tympanic membrane (TM), TM perforation, visible fluid in the middle ear space) as determined by examination with an operating microscope under anesthesia. Based on these criteria, three mice were excluded due to TM perforation.

During ABR and VsEP testing, subcutaneous needle electrodes were placed just posterior to the lambdoidal suture (noninverting), behind the left pinna (inverting), and at the neck (ground). A noninvasive head clip was used to secure the head to a mechanical shaker for delivery of the vestibular stimuli. Auditory stimuli for ABR and DPOAE were delivered via a probe assembly placed at the entrance of the external acoustic meatus. DPOAE, ABR, and VsEP recordings were performed in each mouse, during the same test session, after which the mouse was euthanized. Temporal bones were harvested from mice representative of young, middle, and old age groups for imaging via scanning electron microscope. Stimuli for VsEP, ABR, and DPOAE are described in detail below. Table 1 lists the number of data points attained for each measure.

\section{Vestibular-evoked potentials}

VsEP stimulus and recording methods were similar to Jones et al. (2005). A linear jerk pulse was generated using a linear voltage ramp (2 ms duration) routed through a power amplifier, which drove a mechanical shaker (Labworks, Inc. Model E2-203). The applied voltage produced an acceleration ramp, which was measured by an accelerometer (Endevco, Inc., $10 \mathrm{mV} / \mathrm{g}$ where $g=9.8 \mathrm{~m} / \mathrm{s}^{2}$ ). Output of the accelerometer was electronically differentiated to produce voltages proportional to linear jerk $(0.4 \mathrm{~V} / \mathrm{g} / \mathrm{ms})$, which was monitored with an oscilloscope. The linear jerk pulses were coupled noninvasively to the head through a custom platform mounted atop the shaker. Systematically increasing or decreasing the amplitude of the stimulus waveform controlled the amplitude of the stimulus applied to the head. Amplitude of the jerk stimulus was recorded as the mean peak jerk level

\begin{tabular}{lllllll}
\hline \multicolumn{7}{c}{ TABLE 1 } \\
\hline \multicolumn{7}{c}{ Number of data points for each measure } \\
\hline & $8 \mathrm{kHz}$ & $16 \mathrm{kHz}$ & $32 \mathrm{kHz}$ & $41.2 \mathrm{kHz}$ & DPOAE & $V_{s E P}$ \\
\hline Male & 58 & 59 & 59 & 58 & 56 & 56 \\
Female & 71 & 71 & 72 & 72 & 65 & 62 \\
Total & 129 & 130 & 131 & 130 & 121 & 118 \\
\hline
\end{tabular}

The table indicates the number of mice tested for each measure and includes cases where the measurement was performed but there was no measurable response. Eight to 14 animals were tested for each bimonthly age grouping from 2 to 24 months (e.g., $<2$ months, 2-3 months, 4-5 months, 67 months, etc.) 
(measured using an oscilloscope) and was expressed in $\mathrm{dB}$ relative to $1.0 \mathrm{~g} / \mathrm{ms}(\mathrm{dB}$ re: $1.0 \mathrm{~g} / \mathrm{ms})$. Stimulus amplitude ranged from -18 to $+6 \mathrm{~dB}$ re: $1.0 \mathrm{~g} / \mathrm{ms}$ and was adjusted in $3 \mathrm{~dB}$ steps. A broad band forward masker (50-50,000 Hz, $97 \mathrm{~dB}$ SPL) was presented during VsEP measurements to verify absence of cochlear responses (Jones and Jones 1999). Jerk stimuli were presented at 17 pulses per second and had two directions of motion: normal and inverted. Mice were placed in a supine position with nose up and stimuli were presented in the naso-occipital axis. Normal polarity began with upward movement (nasooccipital $+\mathrm{X})$. Inverted stimulus polarity began with downward movement (naso-occipital $-\mathrm{X}$ ). Responses were collected for both normal and inverted polarities and the resulting waveforms were averaged online to produce the final waveform for analysis.

\section{Auditory brainstem responses}

Tone burst stimuli were used to elicit ABRs. Continuous pure tone stimuli were generated by a digital signal analyzer (Stanford Research Systems SR785) and shaped/controlled using custom software and Tucker Davis Technologies (TDT, Alachua, FL, USA) modules (TG6, SW2, PA4). A $10 \mathrm{~V}$ peak-to-peak applied voltage was used to create tone bursts at 8 , 16,32 , and $41.2 \mathrm{kHz}$. Each tone burst had $1.0 \mathrm{~ms}$ risefall times and $1.0 \mathrm{~ms}$ plateau (3 $\mathrm{ms}$ total duration). During ABR testing, a probe assembly was inserted into the mouse ear canal and a calibrated microphone (ER10B+, Etymotic Research) was used to measure sound level. The output from the microphone was routed to an oscilloscope and the acoustic peak-to-peak voltage at the maximum stimulus intensity was recorded. Peak equivalent sound pressure level (peSPL) was then calculated based on the microphone sensitivity as determined by calibration in a custom coupler. Stimuli were presented to the left ear via commercial OAE tips (ER10D-TO5 $5 \mathrm{~mm}$, Etymotic Research) which were tapered at the tip with polyethylene tubing (PE-25). Auditory stimuli were presented at a rate of 17 stimuli per second. Intensity series were collected with a descending series of stimulus levels (6 or $12 \mathrm{~dB}$ steps). Stimulus levels were decreased until no response was visible and then dropped an additional $6-12 \mathrm{~dB}$, in order to ensure that a sub-threshold level had been reached.

\section{Distortion product otoacoustic emissions}

Methods for DPOAE stimuli and recording were similar to Jimenez et al. (1999) and Guimaraes et al. (2004). Stimuli for DPOAEs were generated and shaped using custom software and modules from Tucker Davis Technologies (TDT modules TG6, PA4, and SW2). Pure tone frequencies $(\mathrm{f} 1, \mathrm{f} 2, \mathrm{f} 2 / \mathrm{f1}$ ratio= 1.25), at equal levels ( $\mathrm{L} 1=\mathrm{L} 2=60 \mathrm{~dB}$ SPL), $150 \mathrm{~ms}$ duration, were generated with independent sources (HP Agilent 33220A signal generators) and routed through separate drivers to mix acoustically in the ear canal via the same probe assembly and commercial OAE tips used for ABR testing. Stimulus frequencies for the primaries were such that the geometric mean $\left(\mathrm{GM}=(\mathrm{f} 1 \times \mathrm{f2})^{0.5}\right)$ frequencies ranged from 6.0 to $48.5 \mathrm{kHz}$ (at least eight frequencies per octave). During each study, ear canal sound pressure was recorded with a low noise probe tube microphone (ER 10B+). The microphone output was amplified $10 \times(\mathrm{ER} 10 \mathrm{~B}+$ preamplifier $)$ and input to a dynamic signal analyzer (Stanford Research Systems SRS785) for sampling (at $200 \mathrm{kHz}$ ) and fast Fourier transform (FFT). The amplitude of $\mathrm{f1}, \mathrm{f} 2$, and the 2f1-f2 distortion product was measured from the FFT waveform. The noise floor was measured as the average amplitude in the five frequency bins above and below the 2f1-f2 component. The recording system was tested periodically in a calibration cavity to confirm the absence of artifactual distortion.

\section{Microphone and stimulus calibration}

Stimuli for ABR testing were calibrated using a Bruel \& Kjaar (B \& K) 1/4" microphone (Model 4954), Nexus amplifier (Model 2690), a $0.35 \mathrm{ml}$ custom coupler and custom software. During calibration, the probe tube assembly (housing the ER10B + microphone and exit ports for sound) was inserted into one end of the custom coupler and the B \& $\mathrm{K}$ microphone was inserted into the other end. The output of the ER10B + microphone was amplified $(10 \times)$ and routed to one channel of a SRS785 signal analyzer. The output from the B \& $\mathrm{K}$ microphone was routed to a second channel on the SRS785. Custom softwarecontrolled stimulus generation and signal analysis for DPOAE stimuli. Each stimulus frequency was presented and the PA4 attenuator was adjusted until a level of $60 \mathrm{~dB}$ SPL was achieved for the B \& K channel. The PA4 attenuation level and the ER10B + output level were saved as a probe tube calibration file (PTC) and the ER10B + microphone sensitivity was calculated for each frequency. This PTC file served two purposes. First, during DPOAE testing, the PTC file was loaded into the custom software and was used to calculate the target $\mathrm{dB}$ SPL for the ER10B + microphone output. This assured that a level of $60 \mathrm{~dB}$ SPL was achieved for both primary tones presented during DPOAE testing. Secondly, during ABR testing, the calibration values were used to determine stimulus presentation levels for the four stimulus frequencies tested $(8,16,32$, and $41.2 \mathrm{kHz})$. 
Recording overview and averaging

Measurements in each animal began with DPOAEs followed by ABRs and VsEPs. This order was chosen to limit exposure to high sound pressure levels that might result in a temporary auditory threshold shift. Stimulus levels for DPOAE were limited to $60 \mathrm{~dB}$ SPL compared to ABR maximum stimulus levels, which approached $100 \mathrm{~dB}$ pe SPL. An intense forward masker was presented periodically during VsEPs (average intensity level $97 \mathrm{~dB}$ SPL). Therefore, VsEP testing was performed last. Stimulus frequencies for ABRs and DPOAEs were tested in random order.

Single channel signal averaging was used to record VsEP and ABR response waveforms. The electroencephalographic activity was amplified $(200,000 \times$, Grass P511), band pass filtered $(300-3,000 \mathrm{~Hz},-6 \mathrm{~dB}$ points, Grass P511) and digitized (10 $\mu$ s per point for 1,024 points, TDT AD1) beginning at stimulus onset. Of the samples, 256 were averaged to produce the final VsEP or ABR waveforms. Offline analysis was used to determine response thresholds (in $\mathrm{dB}$ re: $1.0 \mathrm{~g} / \mathrm{ms}$ or $\mathrm{dB}$ peSPL), response peak latencies (in $\mathrm{ms}$ ), and peak-to-peak amplitudes (in $\mu \mathrm{V}$ ).

\section{Data analysis}

In order to compare cochlear and gravity receptor sensitivity, it was necessary to establish a common unit of measure. This was done by normalizing ABR and VsEP threshold values in terms of a percent change in the dynamic range (\% deficit). Dynamic range was defined as the range from the best threshold measured for the strain to the maximum stimulus level that could be presented for $10 \mathrm{~min}$ without causing a temporary threshold shift. A pilot study revealed that levels greater than $100 \mathrm{~dB}$ pe SPL could result in a threshold shift after a 10-min exposure. Therefore, $100 \mathrm{~dB}$ pe SPL was used as the upper limit for the ABR dynamic range. The lower limit for the auditory dynamic range was set by the best threshold obtained for each frequency $(12,13.1,4.9$, and $25.4 \mathrm{~dB}$ pe SPL for the test frequencies $8,16,32$, and $41.2 \mathrm{kHz}$, respectively). The lowest VsEP threshold measured was $-13.5 \mathrm{~dB}$ re: $1.0 \mathrm{~g} / \mathrm{ms}$ and the maximum nonnoxious stimulus presentation level was $+6 \mathrm{~dB}$ re: $1.0 \mathrm{~g} / \mathrm{ms}$. The resulting dynamic range for VsEPs was $19.5 \mathrm{~dB}$. To normalize a given measured threshold $(y)$, the following formula was used:

$$
X(\%)=\left(\frac{y-z}{k}\right) \times 100
$$

where $x=$ the normalized value in percent, $y=$ measured absolute threshold, $z=$ the lowest threshold measured across all studies and $\mathrm{k}$ is the dynamic range.
For example, with a measured absolute threshold of $-7.5 \mathrm{~dB}$ re: $1.0 \mathrm{~g} / \mathrm{ms}$ :

$x=[(-7.5-(-13.5) / 19.5] \times 100$

$x=[6 / 19.5] \times 100$

$x=30.77 \%$

Our emphasis in the present study was to evaluate rates of aging for the vestibular and auditory periphery. To this end, the rate of change with age was expressed in terms of an aging slope (i.e., $\mathrm{dB} /$ month, $\mathrm{ms} / \mathrm{month}$, and $\mu \mathrm{V} /$ month) for response threshold and early response components $\mathrm{P} 1$ latency, and P1-N1 amplitude, respectively. Later peaks (P2 and P3) generated by central neural structures were evaluated in relation to early response peaks.

Auditory and gravity receptor function were evaluated across age using linear regression, analysis of variance and analysis of covariance (ANCOVA) [SPSS 17.0] as noted in the results. Linear regression was used to test relationships between response metrics (i. e., latency, amplitude, and threshold) and age, and to determine the corresponding regression coefficients for rate of aging (slope) and intercept. The general effects of gender were evaluated using ANCOVA with age as a covariate. A student's $t$ test (Zar 1984) was used to test for gender effects and to compare the rate of aging (linear regression slopes) between response metrics. Values of $p<0.05$ were taken to be statistically significant.

\section{Scanning electron microscopy}

Temporal bones from young, middle aged, and old mice were dissected at the end of the functional experiments and fixed using $4 \%$ paraformaldehyde and $2 \%$ glutaraldehyde. Following $24 \mathrm{~h}$ in fixative, the temporal bones were dehydrated using graded concentrations $(70 \%, 90 \%, 95 \%$, and $100 \%)$ of ethyl alcohol. After a minimum of $24 \mathrm{~h}$ in $100 \%$ ethyl alcohol, the gravity receptor organs were microdissected from the temporal bone and mounted on aluminum stubs, critical point dried (Bal-Tec CPD 030, Liechtenstein), and sputter coated (Anatech LTD Hummer 6.6, San Diego, CA, USA). Specimens were imaged with a scanning electron microscope (FEI Quanta 200, Hillsboro, OR, USA). The use of animals reported herein was approved by the Institutional Animal Care and Use Committee at East Carolina University.

\section{RESULTS}

\section{Gender effects}

Response thresholds. Figure 1A illustrates male and female response thresholds for VsEPs as a function of 
age. There were no significant gender effects on VsEP thresholds over the ages studied (ANCOVA, age as covariate). Similarly, there were no significant differences between male and female VsEP aging regression slopes and intercepts ( $t$ tests, Zar 1984). VsEP threshold data for males and females therefore were pooled to evaluate response metrics as a function of age.

ABR studies included stimuli delivered at 8, 16, 32, and $41.2 \mathrm{kHz}$. Threshold data for $8 \mathrm{kHz}$ ABRs are shown in Figure 1B. Gender effects were evident only for ABR thresholds for 8 and $41.2 \mathrm{kHz}(p<0.001, p=$ 0.003 , ANCOVA, threshold by gender with age as covariate) where thresholds for females were lower than those for males. Moreover, the aging slopes for
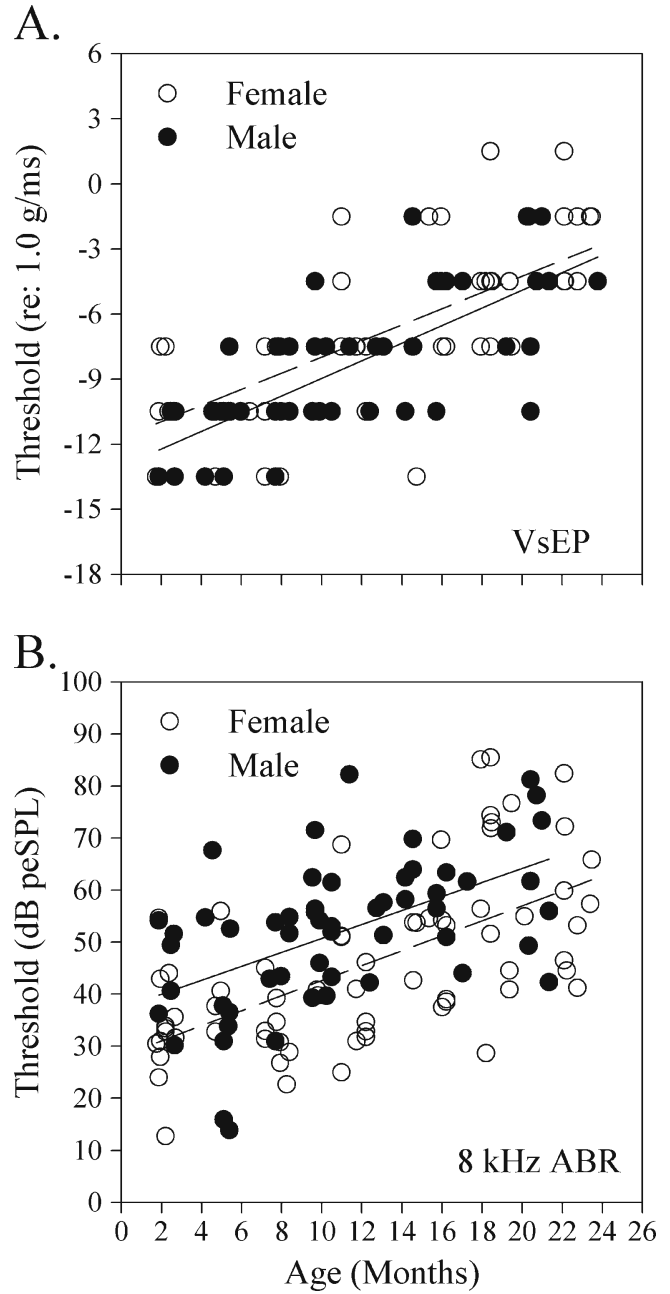

FIG. 1. A Female $(n=62)$ and male $(n=56)$ VsEP thresholds as a function of age. Linear regression equations were $y=-11.70+0.37 x$ (the $95 \%$ confidence interval for slope was $0.27-0.47$ ) and $y=$ $-13.04+0.41 \times$ (the $95 \%$ confidence interval for slope was 0.30 0.52 ) for females and males, respectively. No significant difference was found between females and males for the slope or intercept of the linear regression line. B ABR thresholds at $8 \mathrm{kHz}$ as a function of age for female $(n=71)$ and males $(n=58)$. Linear regression equations were $y=28.18+1.44 \times$ for females (dashed line; the $95 \%$ confidence interval for slope was $0.99-1.88$ ) and $y=37.32+1.34 \times$ for males (solid line; the 95\% confidence interval for slope was 0.77-1.91). male and female thresholds were significantly different for both $8 \mathrm{kHz}$ and $41.2 \mathrm{kHz}$ ABRs $(p<0.01)$. There were no general gender effects on ABR thresholds for 16 and $32 \mathrm{kHz}$ and no differences in aging slopes for males and females at these frequencies.

Regarding the gender differences at $8 \mathrm{kHz}$, the slope for females and males although statistically different were nonetheless physiologically very similar. As can be seen from Figure 1B, the two regression lines are nearly parallel whereas there is a substantive difference in the two intercepts (i.e., 9.1 dB). The difference in intercepts reflects the generally lower thresholds of female animals throughout aging. The $8 \mathrm{kHz}$ aging slope for female thresholds was $1.438 \mathrm{~dB} /$ month, whereas for males it was $1.341 \mathrm{~dB} /$ month. The predicted cumulative difference in threshold produced by these two slopes over the life span of a mouse (approximately 24 months) was about $2.3 \mathrm{~dB}$, which is the predicted maximum difference in threshold that could be attributed to gender differences over time for $8 \mathrm{kHz}$ ABRs. This small difference in threshold is of little practical physiological significance. We therefore pooled $8 \mathrm{kHz}$ threshold data for males and females, and used the pooled data for comparing aging slopes for $8 \mathrm{kHz}$ ABRs with VsEP data. Similarly, since there were no significant gender effects on thresholds for 16 and $32 \mathrm{kHz}$ ABRs, we pooled male and female data to make final estimates of aging effects and comparisons of vestibular and auditory function.

In the case of $41.2 \mathrm{kHz} \mathrm{ABR}$ data, the gender differences were associated with a difference in aging slope between males and females of approximately $0.285 \mathrm{~dB} /$ month. Based on this difference, the estimated cumulative threshold difference over 24 months was approximately $6.8 \mathrm{~dB}$. This predicted gender-based threshold difference was notable and precluded the pooling of threshold data for male and female at this frequency.

Response latencies and amplitudes. There were no general gender effects on peripheral response components for VsEP and ABR P1 latencies or P1N1 amplitudes (ANCOVA). Moreover, there were no differences in aging slopes between genders for VsEP and ABR latencies and amplitudes. Therefore, latency and amplitude data for males and females were combined to obtain final estimates for aging rates and to make comparisons between gravity receptor and cochlear function.

\section{Age effects}

Gravity receptor function. Figure 2 illustrates representative VsEPs recorded in response to $+6 \mathrm{~dB}$ re: $1.0 \mathrm{~g} / \mathrm{ms}$ stimuli at ages between 1.7 and 23.8 months. VsEP responses were generally present at all ages tested. 
Out of 118 animals successfully tested, two had no response (one at 18.4 months and a second at 20.4 months). VsEP waveforms of young adults demonstrated features typical for healthy normal mice (Jones et al., 2005). However, a notable deterioration in waveform morphology occurred as a function of age. The decline in VsEP responses is perhaps best appreciated from Figure 3A, which shows VsEP amplitudes as a function of age. P1-N1 amplitudes for VsEPs decreased significantly as a function of age (regression. $p<0.001, R^{2}=0.195$ ). The rate of decrease on average was approximately $-0.02 \mu \mathrm{V}$ per month (Fig. 3A). The decline in waveform amplitude may also be discerned in Figure 2 by comparing response examples from younger ages with those of 18- and 23month-old animals.

Figure 4 summarizes normalized VsEP threshold data for all animals. VsEP thresholds increased significantly (regression, $p<0.001, R^{2}=0.496$ ) as a function of age. The rate of VsEP threshold increase with age was on average about $0.39 \mathrm{~dB}$ per month (95\% confidence interval was $0.318-0.464)$. At the oldest ages (18-23 months old), mice showed an average loss of $49 \%$ of the response dynamic range. The rate of increase in VsEP thresholds suggested a slow progressive decline in gravity receptor sensitivity that culminated in a moderate loss of sensitivity at

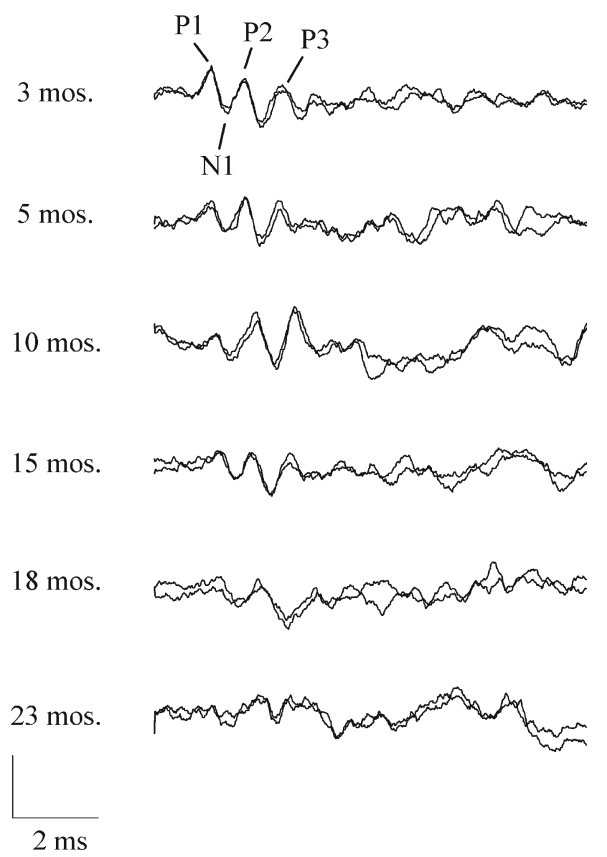

FIG. 2. Representative VsEP response waveforms recorded for six different animals at various ages between 1.7 and 23.8 months-ofage in CBA mice. Stimulus level for all responses was $+6 \mathrm{~dB}$ re: $1.0 \mathrm{~g} /$ ms. Two traces are shown for each age to demonstrate how well responses replicate. Response amplitudes decline and latencies increase with age. Scale bar indicates amplitudes and latency scales for responses. Positive voltages are plotted upward. Notable positive $(\mathrm{P} 1, \mathrm{P} 2, \mathrm{P} 3)$ and negative (N1) peaks are marked.
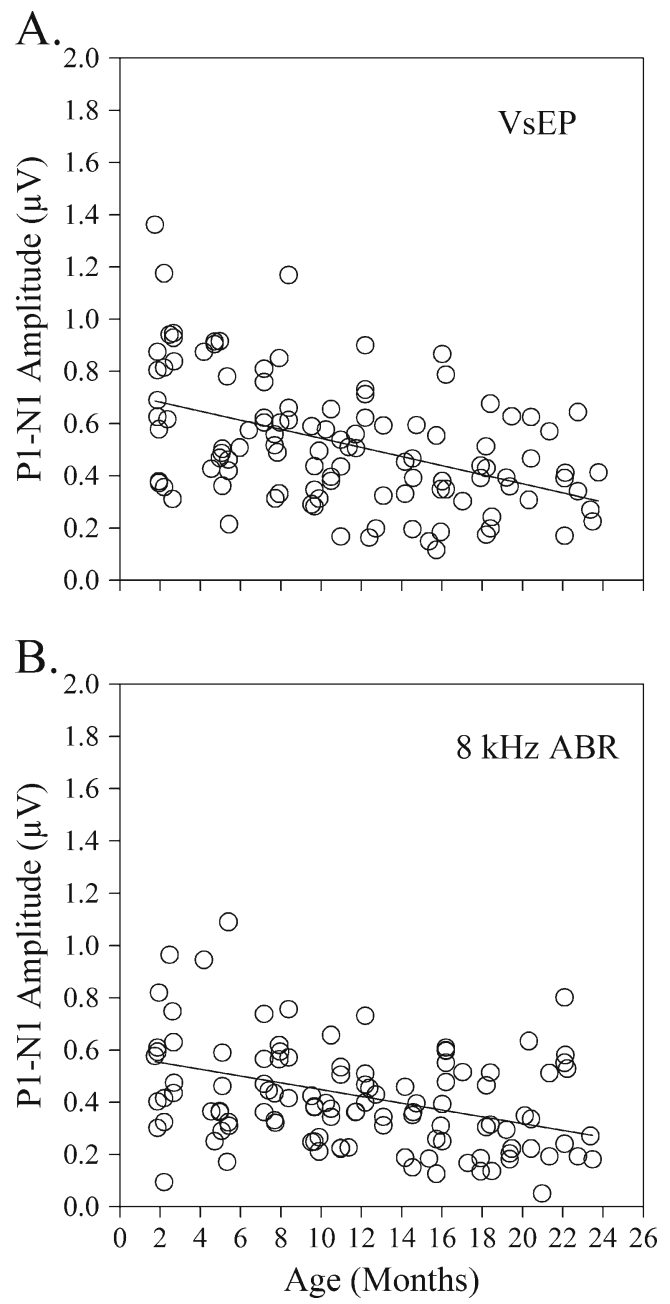

FIG. 3. P1-N1 amplitudes for $\mathrm{VsEP}(n=118)$ and $8 \mathrm{kHz}$ ABR $(n=$ 129) at maximum stimulus levels $(+6 \mathrm{~dB}$ re: $1.0 \mathrm{~g} / \mathrm{ms}$ for $\mathrm{VsEP}$, $100 \mathrm{~dB}$ peSPL for $\mathrm{ABR}$ ) as a function of age. There was a significant decrease in P1-N1 amplitude as a function of age for both ABR and VsEP measures, suggesting a significant decrease in the number of hair cells and primary afferents contributing to the responses.

advanced age. The average rate of decline in dynamic range per month was $2.175 \%$ per month $(95 \%$ confidence interval: 1.757-2.593).

VsEP latencies for P1, P2, and P3 were relatively stable but increased by an average of $0.012 \mathrm{~ms}$ per month (Fig. 5A, P1 regression, $p<0.001, R^{2}=0.171$ ). Latencies for central (P2, P3) and peripheral (P1) peaks tended to increase in parallel with age. P3 was considerably more variable than $\mathrm{P} 1$ and $\mathrm{P} 2$ and was present in less than half the animals.

SEM showed dense populations of otoconia in the utricle and saccule at advanced ages, with similar morphology to that seen at younger ages. There was no obvious decline in otoconia that would explain the observed age-related decrease in gravity receptor sensitivity. Based on data from Jones et al. (2004), a $50 \%$ reduction in P1-N1 amplitude should be accompanied by a $35 \%$ loss of otoconia (i.e., one third of the sensory epithelial surface would be devoid of otoco- 


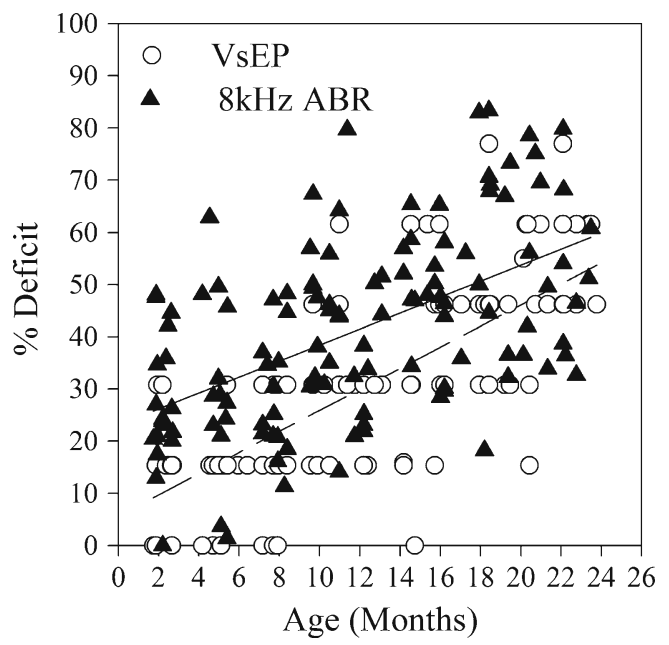

FIG. 4. Normalized thresholds for $\mathrm{VsEP}(n=118)$ and $8 \mathrm{kHz}$ ABR ( $n=$ 129) plotted as a function of age. The average monthly decline in dynamic range was $2.17 \%$ for $\mathrm{VsEP}$ (dashed line) and $1.78 \%$ for $8 \mathrm{kHz}$ (solid line), respectively. The $95 \%$ confidence interval for VsEP and $8 \mathrm{kHz} \%$ deficit slope were $1.76-2.59$ and $1.32-2.22$, respectively. The similar average monthly decreases in dynamic range and considerable overlap of confidence intervals for VsEP and ABR suggest that aging affects the two inner ear sensory systems at a similar rate.

nia) if the cause of the amplitude deficit was entirely due to otoconial abnormalities. In the specimens examined here, we saw no such loss of otoconia.

Auditory function. ABR responses were present for all age groups at all test frequencies. There were significant age effects on ABR thresholds, latencies, and amplitudes for stimulus frequencies of 8,16 , and $32 \mathrm{kHz}$ (ANCOVA, all $p<0.001$ ). Owing to the gender effect noted above for $41.2 \mathrm{kHz}$ ABRs, males and females were evaluated separately for this frequency. Threshold increased with age for both males $(p<0.04)$ and females $(p<0.001)$. However, regression coefficients for latency (P1) and amplitude (P1-N1) were not significant at $41.2 \mathrm{kHz}$.

ABR thresholds increased significantly for 8,16 , and $32 \mathrm{kHz}$ as a function of age (Figs. $1 \mathrm{~B}, 4$ and $6 \mathrm{~A}$ ). The aging slopes for these frequencies were comparable and ranged from 1.15 to $1.38 \mathrm{~dB}$ pe SPL per month. When grouped into 12 age brackets, thresholds for the youngest groups (e.g., 1-8 months) manifested the lowest thresholds, whereas thresholds for successively older groups were correspondingly higher (e.g., Fig. 6A). When normalized in terms of the dynamic range and expressed in percent deficit, the rate of decline in response sensitivity varied from approximately $1.2-1.8 \%$ per month. The average rate of threshold decline for the $8 \mathrm{kHz}$ ABR was $1.78 \%$ per month (95\% confidence interval: 1.32-2.22) and can be seen in Figure 4 (filled triangles). At the oldest ages tested, there was an average decrease (\% deficit) of $25-35 \%$ in auditory dynamic range.
Aging rates for 8,16 , and $32 \mathrm{kHz}$ ABR amplitudes were notable and of similar magnitude (range -0.013 to $-0.021 \mu \mathrm{V} /$ month). ABR amplitudes for P1-N1 decreased as a function of age by approximately $0.016 \mu \mathrm{V}$ per month (average rate for 8, 16, and $32 \mathrm{kHz}$ ABR amplitudes). The decline in amplitudes for $8 \mathrm{kHz}$ ABRs is shown in Figure 3B.

$A B R$ latencies were relatively stable over the lifespan of animals with P1 latency increasing at a shallow rate ranging from approximately $0.007-0.009 \mathrm{~ms}$ per month for 8, 16, and $32 \mathrm{kHz}$ ABRs (all $p<0.001$ ). Aging slopes (latency versus age) for peaks P1, P2 and P3 were comparable as can be seen in Figure 5B for the $8-\mathrm{kHz}$ ABR data.

DPOAEs were present at all ages (Fig. 6B). DPOAE amplitudes decreased as a function of age (ANCOVA, $p=0.002$, frequency as covariate). A comparison of mean DPOAE amplitudes between the youngest and oldest age groups revealed an average $30 \%$ decrease in response amplitudes. However, average amplitudes
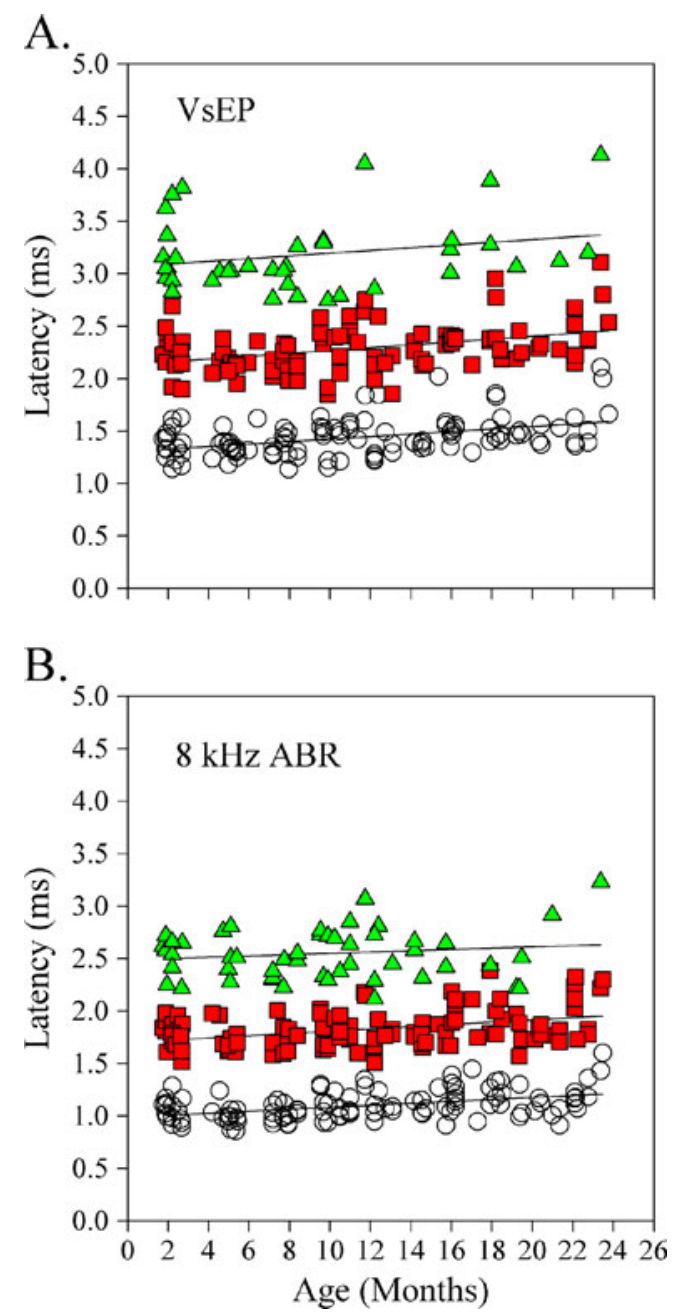

FIG. 5. VsEP and ABR P1 (circles), P2 (red squares), and P3 (green triangles) latencies as a function of age. Stable latencies for $\mathrm{ABR}$ and VsEP suggest minimal age-related change in synaptic temporal mechanisms and activation of primary afferents. 


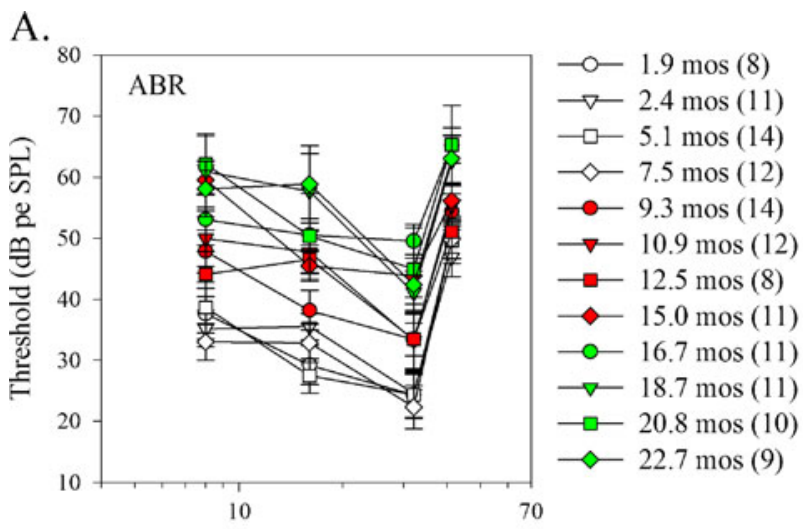

Frequency $(\mathrm{kHz})$

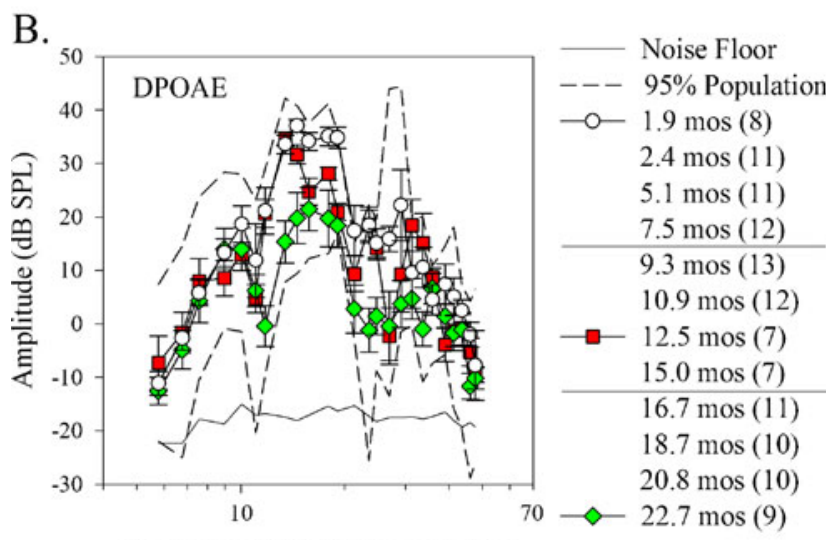

Geometric Mean Frequency (kHz)

FIG. 6. A Mean $A B R$ thresholds plotted against frequency for the data grouped into 12 bi-monthly age groups. Mean ages in months (mos) are listed at the right. Number of animals tested for each age group is shown in parentheses. Error bars represent standard error of the mean. B Mean DPOAE amplitudes as a function of geometric mean frequency for three specific ages representing young, middle, and old animals. Symbols identify the specific ages that appear in the graph. Each plot well represents the data for the surrounding age groups that were not plotted. Number of animals tested for each age group is shown in parentheses. Error bars represent standard error of the mean. The solid black line at the bottom represents the average noise floor and the dashed lines represent the $95 \%$ population range ( \pm 2 standard deviations around the mean) for the 2-3-month age group. Overall, there was minimal decline in DPOAE amplitude with increasing age.

for the oldest ages tested remained within the 95\% population range for the 2-3-month-old group (Fig. 6B). DPOAE results indicate the existence of age-related decreases in outer hair cell function, a finding that is in agreement with the ABR findings of age-related decreased auditory sensitivity.

Comparisons between gravity receptor and auditory function. The results for $8-\mathrm{kHz}$ stimuli were representative of ABR findings generally. Therefore, these data were used for quantitative comparisons of $\mathrm{ABR}$ and VsEP findings.

The rate of decline in function with age for vestibular and auditory responses was similar. P1-N1 amplitudes for VsEPs and ABRs declined at virtually the same rate. Response amplitudes diminished from 0.013 to $0.021 \mu \mathrm{V} /$ month for ABR vs. $0.016 \mu \mathrm{V} /$ month for VsEP, which were not significantly different ( $t$ test, Zar, 1984, see Fig. 3). P1 latencies for both VsEPs and ABRs were relatively stable over time. Latency values for each response increased gradually at slightly different rates with age $(p<0.001$; slopes: $8 \mathrm{kHz}=$ $0.0092 \mathrm{~ms} / \mathrm{month}$ and $\mathrm{VsEP}=0.0012 \mathrm{~ms} / \mathrm{month}$, Fig. 5). The small difference in these two rates of aging would predict that by 24 months of age, ABR onset latencies would be only $0.06 \mathrm{~ms}$ longer than VsEP onset latencies. In addition, gravity receptor and cochlear sensitivities both declined at comparable rates as a function of age (Fig. 4). Based on the normalized dynamic range and linear regression analysis, VsEP thresholds increased at a slightly faster rate than ABR thresholds (2.17\% per month for the VsEP and $1.78 \%$ per month for the ABR, $p<0.001$, Fig. 4). However, the difference in slope was modest and to some extent misleading. It would be incorrect to imply that VsEP thresholds evidence greater deficits with age compared to ABR thresholds. The regression lines in Figure 4 show that, on average, percent deficit for $\mathrm{ABR}$ is somewhat higher at all ages including the oldest. Given the normal variation of threshold values around the regression lines for both VsEP and ABR, the average difference between the two regression lines is modest.

\section{DISCUSSION}

The findings of the present study provide new insight concerning: (1) age-related changes in gravity receptor function in the $\mathrm{CBA} / \mathrm{CaJ}$ strain; and (2) the relationship between gravity receptor and cochlear functional decline with age. The results indicate that there is a comparable gradual age-related degradation of both cochlear and gravity receptor functions with advancing age in the $\mathrm{CBA} / \mathrm{CaJ}$ mouse strain. The similar time course of decline raises the possibility that common aging processes affect the cochlear and gravity receptor organs. Whether this holds true for other mouse strains remains to be seen.

The CBA/CaJ mouse strain is widely used to investigate the environmental and genetic causes of hearing and vestibular disorders. It serves as the background strain for the development of mutant inbred strains that facilitate the study of the genetic origins of syndromic and non-syndromic auditory and vestibular disorders. It is important that hearing and balance function be well characterized over the entire lifespan of this important inbred strain. Mice studied here adequately represent animals well into advanced age given the normal mouse life span of approximately 24 months. 
VsEP results reveal a gradual age-related decline in gravity receptor sensitivity. This is consistent with reported age-related changes in vestibular structure, biochemistry, and cardiovascular supply including pathology and loss of type I and type II hair cells (Rauch et al. 2001; Shiga et al. 2005; Park et al. 1987), pathology of stereocilia/kinocilia (Rosenhall and Rubin 1975; Bloom and Hultcrantz 1994; Nakayama et al. 1994), degradation of the cuticular plate (Anniko 1983; Bloom and Hultcrantz 1994), neural degeneration (Gleeson et al. 1990; Rauch et al. 2001), reduced blood flow (Lyon and Davis 2002), changes in the globular substance and otoconia (Jang et al. 2006; Suzuki et al. 1997; Campos et al. 1990), and increased presence of lipofuscin (Rosenhall and Rubin 1975; Park et al. 1987; Gleeson et al. 1990; Anniko 1983). These structural observations represent human, rat, guinea pig, monkey, and C57BL/6 J inbred mice models. To our knowledge, the effect of age on gravity receptor structures has not been examined specifically in the CBA/CaJ mouse strain, and correlations between structural and functional aging have not been established.

$\mathrm{ABR}$ results (increased thresholds, relatively stable latencies, and decreased amplitudes) along with DPOAE findings (reduced response amplitudes as a function of age) suggest that the cochlear outer hair cells may be one site of declining auditory function. ABR and DPOAE findings here are consistent with reports of progressive age-related decreases in both inner and outer hair cell densities (Spongr et al. 1997), loss of spiral ganglion fibers (Ohlemiller and Gagnon 2004), and confirm and extend previous studies of age related changes in auditory function reported for the $\mathrm{CBA} / \mathrm{CaJ}$ mouse strain (Guimaraes et al. 2004; Henry 2004; Sha et al. 2008).

The finding of reduced sensitivity for both the gravity receptor organs and cochlea raises the possibility that there may be global changes in the peripheral membranous labyrinth of $\mathrm{CBA} / \mathrm{CaJ}$ mice that affect both modalities. What broad acting structural changes might explain the observed functional decline of the cochlea and gravity receptor organs? One possibility might involve $\mathrm{K}^{+}$recycling and maintenance of $\mathrm{K}^{+}$concentration in the endolymph. It is conceivable that pathological changes in the structures that maintain $\mathrm{K}^{+}$ homeostasis such as the stria vascularis and gap unction systems in the cochlea and dark cells in the vestibular organs (Wangemann 2002; Salt et al. 1987) could affect both cochlear and vestibular function. Age-related degenerative changes in the stria vascularis and spiral ligament have been described (Gratton and Schulte 1995; Gratton et al. 1996; Hequembourg and Liberman 2001; Lang et al. 2002; Ohlemiller et al. 2006). To our knowledge, there are no reports describing the effect of age on vestibular dark cells, which are responsible for secreting $\mathrm{K}^{+}$into the endolymph in regions of the vestibular labyrinth (Wangemann 2002).

Although there is evidence for age-related degenerative changes in the stria vascularis and spiral ligament, results concerning the cochlear endolymphatic potential (EP) are mixed. The EP is inherently difficult to measure and varies by measurement site, species, and genetic strain. For example, in gerbils and BALB/cJ mice, the EP has been shown to decline as a function of age (Gratton et al. 1996), whereas the C57BL/6 J and CBA/CaJ mouse strains show no change or limited change in the EP (Lang et al. 2002; Ohlemiller et al. 2006; Wu and Marcus 2003; Sha et al. 2008). The finding that the EP does not decrease with age in the $\mathrm{CBA} / \mathrm{CaJ}$ strain makes it unlikely that this is the underlying basis for the decreased cochlear sensitivities seen here with aging. There may be other unknown membrane transport deficiencies or common metabolic changes that develop with age and thus affect all sensory epithelia in the labyrinth.

Frank pathological changes in the sensory hair cells (primarily OHC of the cochlea, and type I hair cells in the gravity receptor organs) including altered stereocilia are often cited as a primary cause of age-related hearing loss, while loss of spiral ganglion and Scarpa's ganglion fibers is generally considered to be secondary to the loss of hair cells. However, the specific mechanisms behind hair cell degeneration and neuronal loss are not known. One possible explanation is the membrane hypothesis of aging, also known as the mitochondrial clock theory (Seidman 2000; Seidman et al. 2000). This theory proposes that reduced vascular supply, an increase in reactive oxygen metabolites (ROM) and accumulation of mitochondrial DNA (mtDNA) mutations result in apoptosis. Cochlear and vestibular hair cells do not regenerate in humans; therefore, the maintenance and repair of these sensory structures is critical for maintaining cochlear and vestibular function with advancing age. Vascular changes in the cochlea and vestibular organs, including decreased vascular plasticity and permeability (Prazma et al. 1990; Seidman et al. 1996; Lyon and Wanamaker 1993; Gratton et al. 1996), as well as decreased capillary diameter and blood flow (Lyon and Davis 2002) may compromise perfusion and result in reduced oxygen and nutrient delivery as well as reduced aerobic energy metabolism and increased ROM (McFadden et al. 2001). ROMs are toxic molecules that can damage tissue and have been shown to damage mtDNA. The number of mtDNA mutations has been shown to be proportional to aging (Zhang et al. 2002; Markaryan et al. 2006) and as these mutations accumulate with advancing age, mitochondrial metabolic processes become progressively less efficient. Several studies have examined the role of mitochondria dysfunction in ARHL (e.g., Seidman 2000; Seidman et al. 2000, 2002; 
Fischel-Ghodsian et al. 2004; Yamasoba et al. 2007). The extent to which mitochondria and ROM impact inner ear vestibular aging has not been examined.

One common finding in histological studies of the effect of age on cochlear and vestibular structures is the presence of lipofuscin (Anniko 1983; Bohne et al. 1990; Igarashi and Ishii 1990; Li and Hulcrantz 1994; Gleeson et al. 1990; Rosenhall and Rubin 1975; Park et al. 1987), a "wear-and-tear" pigment that is a byproduct of cellular metabolic processes. The lipofuscin pigment results from peroxidation and may have negative effects on cellular function (Jung et al. 2007). Its presence indicates decreased efficiency of cellular metabolic processes which may be indicative of membrane damage or mitochondrial/lysomal damage.

In summary, the current study found that $\mathrm{CBA} / \mathrm{CaJ}$ mice: (1) show no significant gender differences in age related changes in gravity receptor function; (2) demonstrate a gradual progressive decline in gravity receptor sensitivity; and (3) demonstrate that the decline in gravity receptor function follows a similar time course to that observed for auditory changes. The basis for the parallel decline in function is unknown. Substantial loss of otoconia was ruled out as one possible explanation for decreased gravity receptor sensitivity; however, changes affecting the mass or density of the otoconial layer could exist. Decreased vascular perfusion, decreased metabolic efficiency, increased ROM production, increased numbers of mtDNA mutations, and eventual apoptosis of cochlear and vestibular hair cells and afferent neurons are several possible explanations for the observed reduction in auditory and vestibular sensitivity.

The observed decrease in gravity receptor sensitivity in $\mathrm{CBA} / \mathrm{CaJ}$ mice as a function of age is in agreement with reported age-related changes in human vestibular function such as reduced VOR gain. The observed decline in gravity receptor sensitivity is a new finding and should be considered when using the CBA strain for vestibular studies.

\section{ACKNOWLEDGMENTS}

We thank the following individuals for assistance with various aspects of this project: Dr. Paul Vos, Fiona Foley, Jack Hill, Chris Gaines, and Kristal Mills. This research was supported by NIDCD F31 DC008012 (BEM), NIH R01 DC006443 (SMJ), and the American Academy of Audiology Foundation (BEM).

\section{REFERENCES}

Anniko M (1983) The aging vestibular hair cell. Am J Otolaryngol 4 (3):151-160

Baloh RW, Jacobson KM, Socotch TM (1993) The EFfect of Aging on VISUAL-VESTIBULOOCULAR RESPONSES. Exp Brain Res 95(3):509-516
Bohne BA, Gruner MM, Harding GW (1990) Morphological correLATES OF AGING IN THE CHINCHILLA COCHLEA. Hear Res 48:79-91

Bloom D, Hultcrantz M (1994) Vestibular morphology in relation TO AGE AND CIRCLING BEHAVIOR. Acta Otolaryngol 114(4):387-392

Campos A, Canizares FJ, Sanchez-Quevedo MC, Romero PJ (1990) OtOCONIAL DEgENERATION IN THE AGED UtRicle AND SACCULE. Adv Otorhinolarygol 45:143-153

Enrietto AJ, Jacobson KM, Baloh RW (1999) Aging efFects on AUDITORY AND VESTIBULAR RESPONSES: A LONGITUDINAL STUdy. Am J Otolaryngol 20(6):371-378

Furman JM, Redfern MS (2001) Effect of aging on the OtolithocUlar REFLEX. J Vest Res 11(2):91-103

Fischel-Ghodsian N, Kopke RD, Ge X (2004) Mitochondrial DYSFUNCTION IN HEARING LOSS. Mitochondrion 4:675-694

Gleeson MJ, Felix H, Johnsson LG (1990) Ultrastructural aspects OF THE hUMAN PERIPHERAL VestibUlar sYSTem. Acta Otolaryngol Suppl 470:80-87

Gratton MA, Schulte BA (1995) Alterations in microvasculature are ASSOCIATED WITH ATROPHY OF THE STRIA VASCULARIS IN QUIET-AGED GERBILS. Hear Res 82:44-52

Gratton MA, Schmiedt RA, Schulte BA (1996) Age-Related decreases IN ENDOCOCHLEAR POTENTIAL ARE ASSOCIATED WITH VASCULAR ABNORMALITIES IN THE STRIA VASCULARIS. Hear Res 94:116-124

Guimaraes P, Zhu X, Cannon T, Kim S, Frisina RD (2004) Sex DIFFERENCES IN DISTORTION PRODUCT OTOACOUSTIC EMISSIONS AS A FUNCTION OF AGE IN CBA MICE. Hear Res 192:83-89

HeNRY KR (2004) Males Lose HEARING EARLIER IN MOUSE MODELS OF LATEONSET AGE-RELATED HEARING LOSS; FEMALES LOSE HEARING EARLIER IN MOUSE MODELS OF EARLI-ONSET HEARING LOSS. Hear Res 190:141-148

Henry KR, McGinn MD (1992) The mouse as a model for human Audition. A review of the literature. Audiology 31(4):181-189

Hequembourg S, Liberman MC (2001) Spiral ligament pathology: a MAJOR ASPECT OF AGE-RELATED COCHLEAR DEGENERATION IN C57BL/ 6 MICE. J Assoc Res Otolaryngol 2(2):118-129

Hoffman HJ, SkLare DA (2003) Vestibular system problems: Righting THE BALANCE. Assoc Res Otolaryngol Abst 26:133

IgARASHI Y, IshiI T (1990) LipofusCin PIGMENTS IN THE SPIRAL GANGLION OF THE RAT. Eur Arch Otorhinolaryngol 247:189-193

Jang YS, Hwang CH, Shin JY, Bae WY, Kim LS (2006) Age-Related CHANGES ON THE MORPHOLOGY OF THE OTOCONIA. Laryngoscope 116:996-1001

Jimenez AM, Stagner BB, Martin GK, Lonsburz-Martin BL (1999) AgE-RELATEd LOSS OF DISTORTION PRODUCT OTOACOUSTIC EMISSIONS IN FOUR MOUSE STRAINS. Hear Res 138:91-105

Jones SM, Jones TA (1999) Short LATEncy compound action POTENTIALS FROM MAMMALIAN GRAVITY RECEPTOR ORGANS. Hear Res 136:75-85

Jones SM, Erway LC, Yu H, Johnson KR, Jones TA (2004) Gravity RECEPTOR FUNCTION IN MICE WITH GRADED OTOCONIAL DEFICIENCIES. Hear Res 191:34-40

Jones SM, Johnson KR, Yu H, Erway LC, Alagramam KN, Pollak N, Jones TA (2005) A QUANTITATIVE SURVEY OF GRAVITY RECEPTOR FUNCTION IN MUTANT MOUSE STRAINS. J Assoc Res Otolaryngol 6 (4):297-310

Jones SM, Jones TA, Johnson KR, Yu H, Erway LC, Zheng QY (2006) A COMPARISON OF VESTIBULAR AND AUDITORY PHENOTYPES IN INBRED MOUSE STRAINs. Brain Res 1091(1):40-46

Jung T, Bader N, Grune T (2007) Lipofuscin formation, distribution, AND METABOLIC CONSEQUencEs. Ann NY Acad Sci 1119:97-111

Lang H, Schulte BA, Schmeidt RA (2002) Endocochlear potentials AND COMPOUND ACTION POTENTIAL RECOVERY: FUNCTIONS IN THE C57BL/6 J Mouse. Hear Res 172:118-126

Li HS, Borg E (1991) Age-Related loss of auditory SENSITIVITy IN two MOUSE GENOTYPES. Acta Otolaryngol 111(5):827-834

Li HS, Hulcrantz M (1994) Age-Related degeneration of the organ OF CORTI IN TWO GENOTYPES OF MICE. ORL J Otorhinolaryngol Relat Spec 56(2):61-67 
Lyon MJ, Wanamaker HH (1993) Blood Flow ASSESSMENT OF CAPILLARIES IN THE AGING RAT POSTERIOR CANAL CRISTA. Hear Res 67:157-165

Lyon MJ, Davis JR (2002) Age-related blood flow and Capillary CHANGES IN THE RAT UTRICULAR MACULA: A QUANTITATIVE STEREOLOGICAL AND MICROSPHERE STUDY. J Assoc Res Otolaryngol 3(2):167-173

Markaryan A, Nelson EG, Hinojosa R (2006) Detection of mitochonDRIAL DNA DELETIONS IN THE COCHLEA AND ITS STRUCTURAL ELEMENTS FROM ARCHIVAL HUMAN TEMPORAL BONE TISSUE. Mutat Res 640 (1-2):3845

McFadden SL, Ding D, Salvi R (2001) Anatomical, metabolic and GENETIC ASPECTS OF AGe-RELATEd hEARING loss in mice. Audiol 40:313-321

Nakayama M, Helfert RH, Konrad HR, Caspary DM (1994) Scanning ELECTRON MICROSCOPIC EVALUATION OF AGE-RELATED CHANGES IN THE RAT VESTIBULAR EPITHELIUM. Otolaryngol Head Neck Surg 111(6):799806

Ohlemiller KK (2004) Age-Related hearing loss: the status of SchukneCht's typology. Curr Opin Otolaryngol Head Neck Surg 12:439-443

Ohlemiller KK (2006) CONTRibutions OF MOUSE MODELS TO UNDERSTANDING OF AGE- AND NOISE-RELATED HEARING LOSS. Brain Res 1091 (1):89-102

Ohlemiller KK, Gagnon PM (2004) Apical-to-BASAl gradients In AGERELATED COCHLEAR DEGENERATION AND THEIR RELATIONSHIP TO "PRIMARY" LOSS OF COCHLEAR NEURONS. J Comp Neurol 479:109-116

Ohlemiller KK, Frisina RD (2008) Clinical characterization of ageRELATED HEARING LOSS AND ITS NEURAL AND MOLECULAR BASES. In: Schacht J, Popper A, Fay RR (eds) Auditory trauma: protection and treatment. Springer, New York, pp 145-194

Ohlemiller KK, Lett JM, Gagnon PM (2006) Cellular correlates of AGE-RELATED ENDOCOCHLEAR POTENTIAL REDUCTION IN A MOUSE MODEL. Hear Res 220:10-26

Park JC, Hubel SB, Woods AD (1987) Morphometric analysis and fine STRUCtURe OF the VEstibular ePITHELIUM OF AGED C57BL/6NNia MICE. Hear Res 28:87-96

Paige GD (1992) Senescence of human Visual-Vestibular interactions, 1. Vestibulo-ocular reflex and adaptive plasticity with aging. J Vestib Res 2(2):133-151

Paige GD (1994) Senescence of human visual-vestibular interactions: SMOOTH PURSUIT, OPTOKINETIC, AND VESTIBULAR CONTROL OF EYE MOVEMENTS WITH AGING. Exp Brain Res 98(2):355-372

Prazma J, Carrasco VN, Butler B, Waters G, Anderson T, Pillsbury HC (1990) COCHLEAR MICROCIRCULATION IN YOUNG AND OLD GERBILS. Arch Otolaryngol Head Neck Surg 116(8):932-936

Rauch SD, Velazquez-Villaseñor L, Dimitri PS, Merchant SN (2001) DeCREASING hair Cell COUNTS IN AgING humans. Ann NY Acad Sci 942:220-277
Rosenhall U, Rubin W (1975) Degenerative changes in the human VESTIBULAR SENSORY EPITHELIA. Acta Otolaryngol 79(1-2):67-80

Salt AN, Melichar I, Thalmann R (1987) Mechanisms of endocoCHLEAR POTENTIAL GENERATION BY STRIA VASCULARIS. Laryngoscope 97:984-991

SchukNeCht HF, Gacek MR (1993) Cochlear Pathology in PResbycusis. Ann Otol Rhinol Laryngol 102(1 Pt 2):1-16

SEIDMAN MD (2000) EFFECTS OF DIETARY RESTRICTION AND ANTIOXIDANTS ON PRESBYACUSIS. Laryngoscope 110(5):726-738

Seidman MD, Bai U, Khan MJ, Murphy MJ, Quirk WS, Castora FL, Hinojosa R (1996) Association of mitochondrial DNA deletions AND COCHLEAR PATHOLOGY. A MOLECULAR BiOLOGIC TOOL. Laryngoscope 106(6):777-783

Seidman MD, Khan MJ, Bai U, Shiwany N, Quirk WS (2000) Biologic ACTIVITY OF MITOCHONDRIAL METABOLITES ON AGING AND AGE-RELATED HEARING LOSS. Am J Otol 21(2):161-167

Seidman MD, Khan MJ, Tan WX, Quirk WS (2002) Influence of LECITHIN ON MITOCHONDRIAL DNA AND AGE-RELATED HEARING LOSS. Otolaryngol Head Neck Surg 127(3):138-144

Sha SH, Kanicki A, Dootz G, Talaska AE, Halsey K, Dolan D, Altschuler R, Schacht J (2008) Age-Related auditory pathology IN THE CBA/J MOUSE. Hear Res 243:87-94

Shiga A, Nakagawa T, Nakayama M, Endo T, Iguchi F, Kim TS, Natto Y, Ito J (2005) Aging eFFects on Vestibulo-ocular RESPONSES IN C57BL/ 6 MICE: COMPARISON WITH ALTERATION IN AUDITORY FUNCTION. Audiol Neurootol 10:97-104

Spongr VP, Flood DG, Frisina RD, Salvi RD (1997) Quantitative MEASURES OF HAIR CELL LOSS IN CBA AND C57BL/6 J MICE THROUghout their Life spans. J Acoust Soc Amer 101(6):35463553

Suzuki H, Ikeda K, Takasaka T (1997) Age-Related changes of the GLOBULAR SUbSTANCE IN THE OTOCONIAL MEMBRANE OF MicE. Laryngoscope 107:378-381

WANGEMANN P (2002) $\mathrm{K}^{+}$CYCLING AND THE ENDOCOCHLEAR POTENTIAL. Hear Res 165:1-9

Wu T, Marcus DC (2003) Age-Related changes in cochlear endolymphatic potassium and potential in CD-1 and CBA/CaJ mice. J Assoc Res Otolaryngol 4(3):353-362

Yamasoba T, Someya S, Yamada C, Weindruch R, Prolla TA, Tanokura M (2007) ROLE OF MITOCHONDRIAL DYSFUNCTION AND MITOCHONDRIAL DNA MUtATIONS IN AGE-RELATED HEARING LOSS. Hear Res 226:185193

Zar JH (1984) Biostatistical analysis 2nd Edition. Prentice Hall Inc., Englewood Cliffs

Zhang X, Han D, Ding D, Dai P, Yang W, Jiang S, Salvi R (2002) COCHLEAR MITOCHONDRIAL DNA3867BP DELETION IN AGED MICE. Chin Med J (Engl) 115(9):1390-1393 